\title{
Potentiation of the Toxic Effects of Acetaminophen in Mice by Concurrent Infection with Influenza B Virus: a Possible Mechanism for Human Reye's Syndrome?
}

\author{
M. G. MACDONALD, ${ }^{(37)}$ P. P. McGRATH, D. N. MCMARTIN, G. C. WASHINGTON, AND G. HUDAK \\ Department of Child Health and Development, George Washington Universitv, Washington, D.C. and Division \\ of Biochemistry and Biophysics, Office of Biologics, Food and Drug Administration, Bethesda, Maryland, USA
}

\begin{abstract}
Summary
Using weanling mice of two different genetic strains we demonstrated a potentiation of the toxic effects of acetaminophen by prior infection with influenza $B$ virus. The $C 57 \mathrm{BL} / 6 \mathrm{~N}$ (B6) strain of mice is genetically predisposed to increased toxicity from acetaminophen when the hepatic cytochrome $\mathrm{P}-450$ mixed function oxidase system is preinduced. When $\mathrm{B} 6$ animals are pretreated with influenza $B$ virus and an mixed function oxidase system inducing agent before administering acetaminophen, we observed a significant incidence of atypical "fatty" liver pathology on light microscopy similar to the microvesicular steatosis seen in human Reye's syndrome. Electron microscopic changes in the liver of these animals resemble those published to date in human Reye's syndrome.
\end{abstract}

Abbreviations

EID $_{50}$, egg infectious dose $\mathbf{5 0 \%}$

EM, electron microscopy

ER, endoplasmic reticulum

LM, light microscopy

3-MC, 3-methylcholanthrene

MFO, mixed function oxidase

PAS, periodic acid Shiff's reagent

RS, Reye's syndrome

SER, smooth endoplasmic reticulum

TCID $_{50}$, tissue culture infectious dose, $\mathbf{5 0} \%$

$\mathrm{MID}_{50}$, mouse infectious dose

This study was designed to test the hypothesis, now supported by several investigators, that RS in humans may be caused by the interaction of viruses, environmental factors, and host genetic factors. There is a body of animal data demonstrating the potentiation of effects of viral infection on the host by chemical agents, especially insecticides $(6,8,16)$. Acetaminophen toxicity has been shown to be potentiated by alcohol, and in two patients with mononucleosis $(9,13,23)$. Theophylline toxicity is increased by concomitant infection with either influenza $A$ or influenza B virus $(12,20)$. Viral potentiation of certain chemical toxins, e.g., 4-pentenoic acid and aflatoxin, results in an experimental syndrome very similar to human $\operatorname{RS}(4,24,32)$. Possible explanations for these effects include the adverse effects of xenobiotics on the integrity and function of the immune system, and effects related to the biotransformation of foreign agents, which may be metabolized to pharmacologically active intermediates by components of the cytochrome P-450 MFO system.

RS, or very similar clinical disorders, are found in many different geographic regions of the world. A review of the literature would suggest that RS can be precipitated by many chemically unrelated compounds, each of which has the capacity to cause subclinical, biochemical, and functional abnormalities of the liver and immune system.

We elected to study the effects of influenza B virus infection (which is commonly implicated in the prodromal illness before onset of RS) on two inbred strains of mice which are known to differ significantly in the way that their hepatic MFO system responds to chemical agents. We chose to study acetaminophen for two reasons. First, because it is a commonly used antipyretic in children which is being promoted in the USA, and can be obtained without prescription. Second, because the metabolic pathways for the drug have been well worked out and linked with the aromatic hydrocarbon responsiveness of the MFO system in mice.

In general, all highly lipophilic xenobiotics are rendered more water soluble and hence, more readily excreted, by the microsomal MFO enzyme system located in the SER of the liver and other tisues. Molecular oxygen and reduced NADPH are required for the reaction. Induction of this enzyme system is associated with an increase in microscopically visible SER, and it is interesting that proliferation of SER has been previously reported in cases of RS $(2,26)$. Most MFO reactions are mediated through the hemeprotein cytochrome P-450.

Mitchell, et al. (14) showed that acetaminophen-induced hepatic necrosis is caused by a toxic metabolite of the drug, which binds covalently to tissue macromolecules, including nucleic acids and proteins. The toxic metabolite represents a small part of the original dose of acetaminophen (approximately $4 \%$ ) when the drug is taken in therapeutic doses. The majority of the drug is conjugated directly with sulfate of glucuronide and then excreted. The toxic metabolite shown in Figure 1 is thought to be produced by metabolism via the cytochrome P-450 enzyme system. This metabolite is detoxified by preferential conjugation with a nucleophilic sulphydryl tripeptide, glutathione. In animal studies, when glutathione in the liver is either depleted (e.g., due to malnutrition) or overwhelmed by a very large dose of acetaminophen, the activated metabolite remains unconjugated and free to combine covalently with vital nucleophilic macromolecules in the hepatocyte, leading to eventual hepatic cell death in a typical centrolobular distribution (Fig. 2).

Thorgeirseen, et al. (30) linked metabolism of acetaminophen by the cytochrom P-450 system to the inducibility of aryl hydrocarbon hydroxylase in inbred mice. The degree of aryl hydrocarbon hydroxylase responsiveness has, in turn, been linked to the presence or absence of the gene locus known as the Ah locus, which is inherited as an autosomal dominant in mice (31). There 
is suggestive evidence in the literature that a similar gene locus may exist in man $(1,11)$. C57BL/6N (B6) mice possess the Ah locus and a hepatic microsomal MFO system, which is responsive to induction by aromatic hydrocarbons such as 3-MC and benzo(a)pyrene. The DBA/2N (D2) mice apparently have a different allele at the Ah locus and are relatively unresponsive to hepatic microsomal induction by aromatic hydrocarbons.

Inducers of cytochrome P-450-associated MFO activity, such as 3-MC and phenobarbital, are known to increase the toxicity of acetaminophen, presumably by increasing the quantity of acetaminophen converted to the toxic metabolite. These inducing agents have also been shown to increase covalent binding of acetaminophen to liver tissue, both in vivo and in vitro (14). The aims of the study were 3 -fold. 1) To determine whether morbidity and/or mortality is increased in mice given sublethal doses of influenza $\mathrm{B}$ and acetaminophen, when compared with mice receiving either agent alone. 2) To determine whether increased morbidity or mortality resulting from administration of influenza $\mathrm{B}$ and acetaminophen is associated with aromatic hydrocarbon responsiveness of the MFO system (i.e., presence or absence of the Ah locus) in inbred mice. 3) To determine whether the histologic changes produced in the liver by these agents are "similar" or "dissimilar" to those seen in RS in humans, using LM and EM.

\section{MATERIALS AND METHODS}

B6 and D2 mice of both sexes were supplied by the National Institutes of Health, Small Animal Division. The mice were kept in plastic cages, on standard soft wood bedding, and fed Wayne lab chow ad libitum. An automatic day/night cycle (12 h to 12 h) was maintained and exposure to pharmacologically active compounds such as cigarette smoke, insecticides, and pine or cedar bedding were prevented. Animals infected with influenza

THE FATE OF TOXIC METABOLITES AFTER A LARGE DOSE OF ACETAMINOPHEN

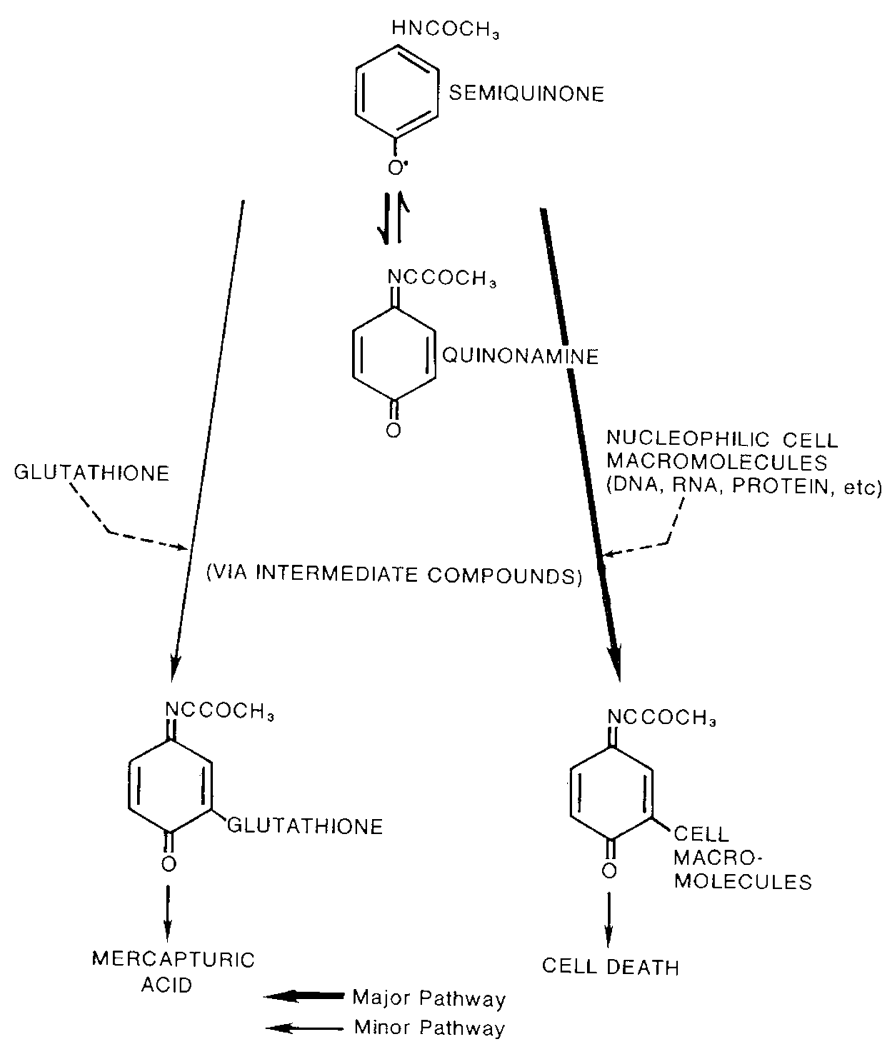

Fig. 1.
B virus were housed separately. Animals were studied at the postconceptual age of $50 \mathrm{~d}$ ( $4 \mathrm{~d}$ postweaning). A pilot study was first run to determine dosage regimens for acetaminophen and influenza $B$ virus, and to determine the normal structure of mouse liver under the EM.

Nonmouse-adapted $\mathrm{B} / \mathrm{Hk} / 73$ seed virus was obtained from the Division of Virology, Bureau of Biologics, U.S. Food and Drug Administration, and initial virus pools were prepared by allantoic inoculation of 9-d-old embryonated eggs. Serial dilutions were then made and injected into 9-d-old embryonated eggs and onto tissue culture plates containing MDCK (canine kidney) cells. The tissue culture plates included liquid overlay, containing trypsin for proteolytic cleavage of the hemagglutinin. Both eggs and tissue cutures were incubated for $72 \mathrm{~h}$. Postinoculation allantoic fluid samples were tested for hemagglutination of chick cells, and culture monolayers were tested for hemabsorbtion, using guinea pig erythrocytes. In this way, the $\mathrm{TCID}_{50}$ and $\mathrm{EID}_{50}$ were determined.

To determine the MID $_{50}$, serial 10-fold dilutions of virus were inoculated into mice pernasally, under light ether anesthesia, using $0.05 \mathrm{ml}$ of dilute virus. Forty-eight hours postinoculation the lungs were removed, homogenized in Hank's solution, and inoculated into 9-d-old embryonated eggs. Using a dose of virus 100 times the $\mathrm{MID}_{50}$, we found that virus from lung homogenates from over $90 \%$ of study mice would regrow in 9-d-old embryonated eggs after $72 \mathrm{~h}$ incubation. Time-course studies gave a period of true infectivity for our mouse population of 7-8 d postinfection. Infection was not associated with readily recognized symptoms. Lung pathology was rarely recognized histologically; minor lung consolidation occurred in approximately $3 \%$ of the animals.

Twenty-four hours after virus inoculation, $80 \mathrm{mg} / \mathrm{kg}, 3-\mathrm{MC}$ was administered intraperitoneally. Twenty-four hours later acetaminophen was administered intraperitoneally (range $150-$ $300 \mathrm{mg} / \mathrm{kg}$ ). Surviving animals were killed by cervical dislocation, $48 \mathrm{~h}$ after receiving acetaminophen.

Control groups received: l) sterile saline alone or in combination with virus, acetaminophen, or 3-MC;2) sterile allantoic fluid alone, or in combination with one or two of the agents in $1)$; 2) virus, acetaminophen, or 3-MC individually or in combination with one of the two other active agents.

Each group consisted of approximately 100 animals. Each experiment was carried out in duplicate, leading to a total $n$ of approximately 200/group; however, liver samples from animals dying spontaneously were not examined because personnel were not available to collect samples at the time of death. This was taken into account for purposes of statistical analysis.

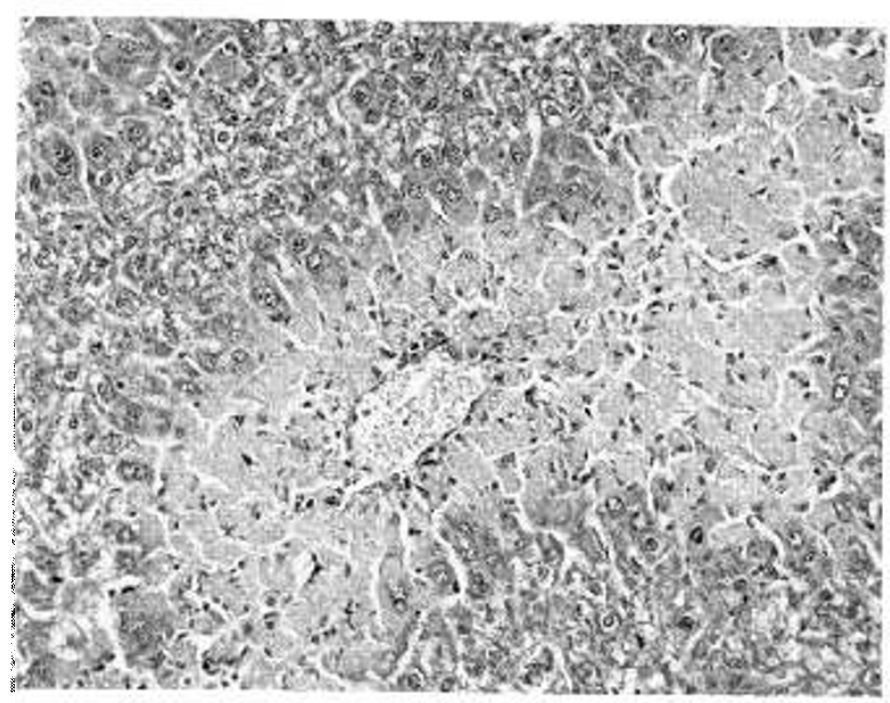

Fig. 2. A section of mouse liver showing the typical centrolobular necrosis caused by acetaminophen. 
Liver samples were taken immediately into glutaraldehyde for EM. Other liver samples from the same animals were prepared appropriately for frozen section, and subsequently stained with Oil-red-O for lipid. Further samples were fixed in Bouins for Giemsa and PAS staining, or homogenized for microsomal preparation. Sections for LM were prepared by Baker Histology (Great Falls, VA) and were examined by two of us, M.G.M. and D.N., a veterinary pathologist. D.N. was unaware of which treatment schedule the animals had received. Necrotic and nonnecrotic lesions were quantified and graded by the method of Chalkley (3).

Seventy number coded electron microscopic samples, representative of study groups and controls, were examined by P.M. and G.W., also without knowledge of treatment schedule. When macroscopic lesions were recognizable in the liver, representative sections were taken from these areas and, when possible, also from apparently normal areas of the same livers.

Microsomal preparations were made from the livers from 15 animals in each study group (including controls) (33). The animals were killed by cervical dislocation. The livers were immediately removed and, after rapid collection of specimens for LM, weighed and washed with ice cold $0.02 \mathrm{M}$ Tris- $\mathrm{HCl} / 0.15 \mathrm{M}$ $\mathrm{KCL}$ buffer, $\mathrm{pH} 7.4$. They were then homogenized in $1.5 \mathrm{vol}-$ umes of the same buffer, using a glass homogenizer with a Teflon pestle. The homogenate was centrifuged at $12,000 \mathrm{~g}$ for $15 \mathrm{~min}$, and the supernatant was decanted through a double layer of fine meshed gauze. The supernatant was then centrifuged at 105,000 $g$ for $45 \mathrm{~min}$ at $4^{\circ} \mathrm{C}$. The resulting pellet was washed by resus-

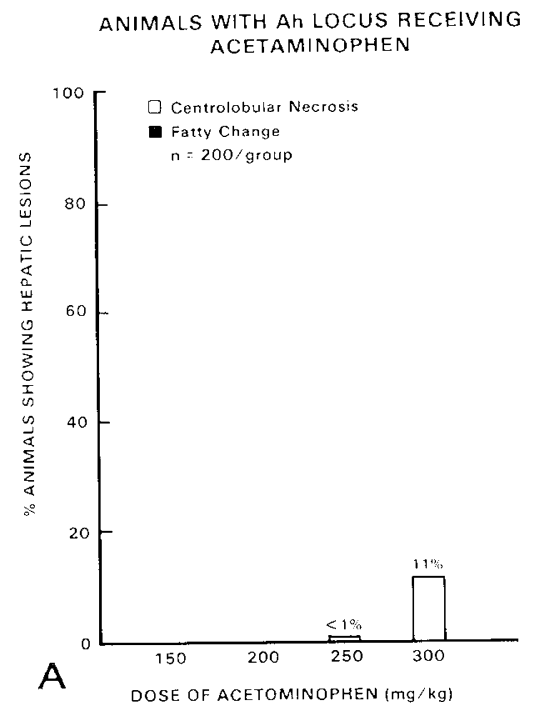

ANIMALS WITHOUT Ah LOCUS

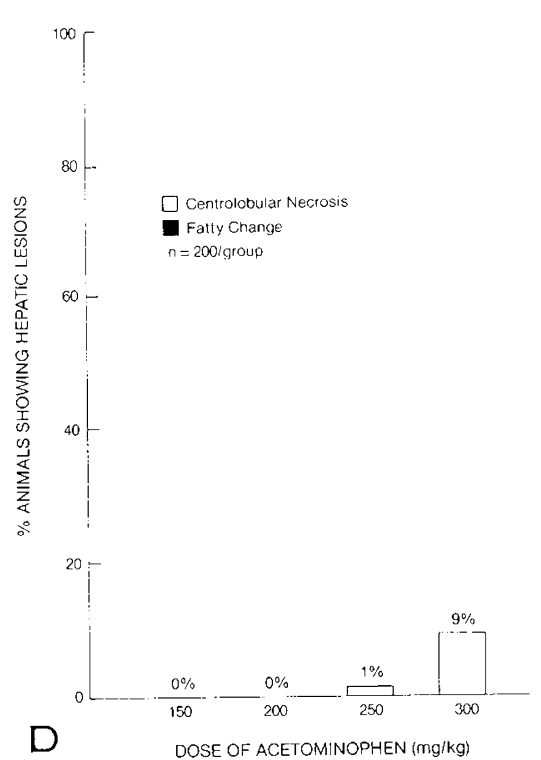

ANIMALS WITH Ah LOCUS RECEIVING ACETAMINOPHEN AND INFLUENZA B VIRUS

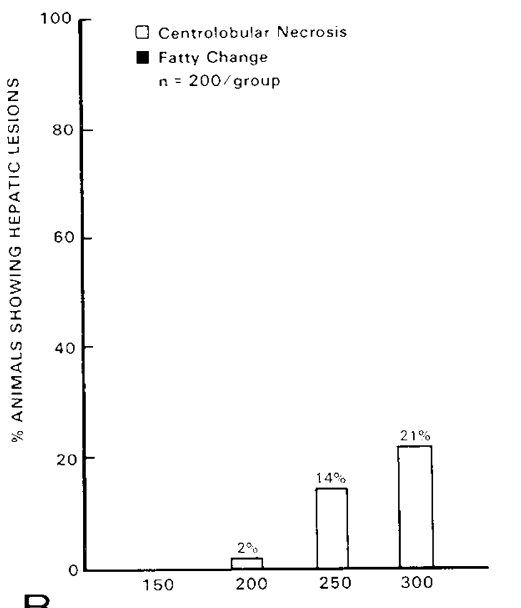

$\mathrm{B}$

DOSE OF ACETOMINOPHEN $(\mathrm{mg} / \mathrm{kg})$

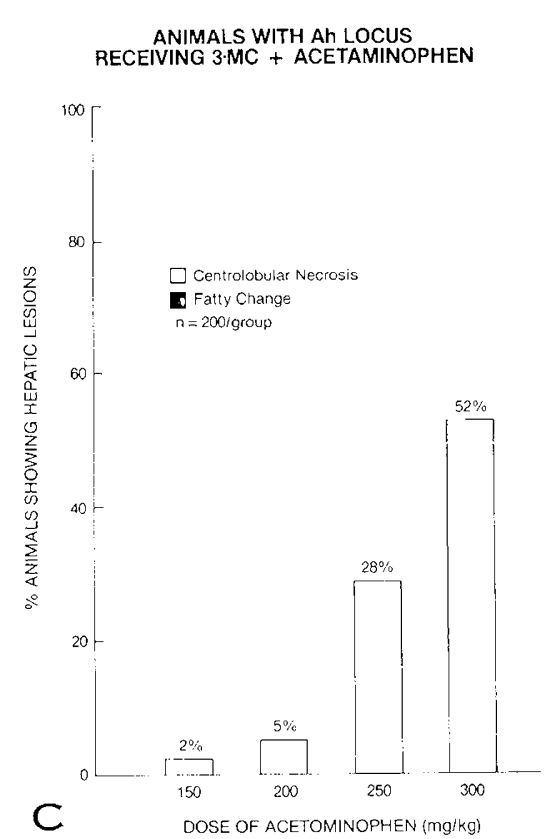

ANIMALS WITH Ah LOCUS RECEIVING INFLUENZA B VIRUS + 3-MC + ACETAMINOPHEN

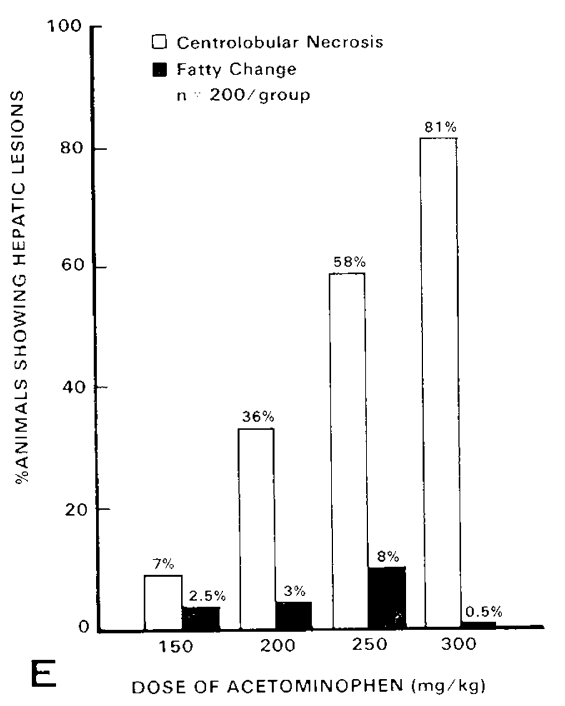

ANIMALS WITHOUT Ah LOCUS RECEIVING INFLUENZA B VIRUS + 3-MC + ACETAMINOPHEN

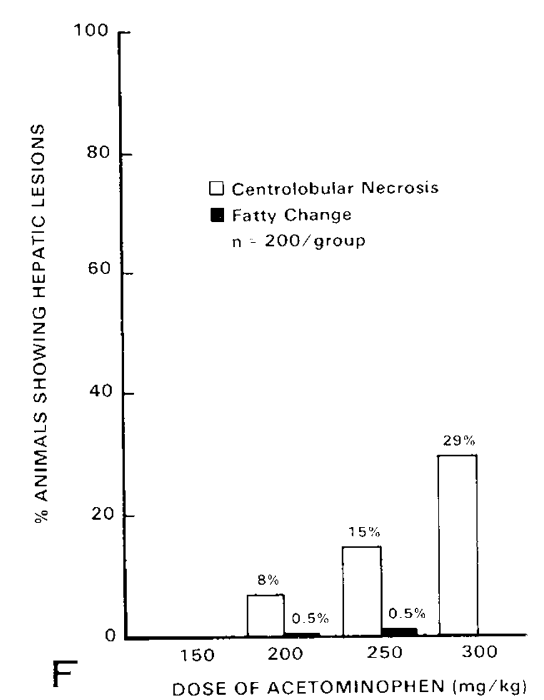

Fig. 3A

Fig. 3B

Fig. 3C

Fig. 3D

Fig. 3E

Fig. 3F 
pension in $0.1 \mathrm{M}$ sodium pyrophosphate buffer, $\mathrm{pH} 7.4$, to remove remaining hemoglobin and recentrifuged at $105,000 \mathrm{~g}$ for $45 \mathrm{~min}$. The pellet was resuspended in $2 \mathrm{ml}$ of $0.02 \mathrm{M}$ Tris$\mathrm{HCl} / 0.15 \mathrm{M} \mathrm{KCL}$ buffer.

Enzyme assay. The protein concentration of the microsomal suspension was determined by the method of Schacterle and Pollack (25) and the cyrochrome P-450 concentration by the method of Omura and Sato (17) from the CO difference spectra of reduced microsomes, using an extinction coefficient of 91 $\mathrm{mM}-1 \mathrm{~cm}-1$ for $\Delta 490-450 \mathrm{~nm}$.

\section{RESULTS}

\section{$L M$ findings (34).}

1) When acetaminophen was given alone, significant centrolubular necrotic lesions (35) typical of acetaminophen toxicity were first recognized on LM at a dose of 300 $\mathrm{mg} / \mathrm{kg}$ in both B6 and D2 mice (Fig. 3a).

2) When acetaminophen was given to $B 6$ and $D 2$ animals preinfected with influenza $B$ virus, significant centrolobular necrosis first appeared at a dose of $200 \mathrm{mg} / \mathrm{kg}$ suggesting some potentiation of acetaminophen toxicity by the virus (Fig. 3b).

3) When the cytochrome P-450 enzyme system was induced with 3-MC, as would be expected, the toxic effects of acetaminophen were markedly potentiated in the B6 mice, and significant centrolobular lesions were first recognized in these animals at a dose of $150 \mathrm{mg} / \mathrm{kg}$ (Fig. $3 c)$. A minor potentiation of acetaminophen effect was seen in D2 animals (Fig. 3d).

4) Significant potentiation of the toxic effects of acetaminophen was recognized in both B6 and D2 animals when pretreated with influenza virus before receiving acetaminophen and 3-MC (Fig. 3e and f). In a small number of animals, treated with all three agents, we recognized the appearance of a distinct histologic pathology in the liver: a diffuse microvesicular steatosis. Sixty percent of those with microvesicular steatosis did not have coexisting centrolobular necrosis. The incidence of this finding was significantly greater in the B6 animals, and appeared to be dose related over the range $150-250 \mathrm{mg} / \mathrm{kilo}$.

5) Mortality (within $48 \mathrm{~h}$ of acetaminophen administration) was markedly increased in B6 animals, by prior induction of the MFO system with 3-MC when acetaminophen was given at a dose of $250 \mathrm{mg} / \mathrm{kilo}$, in non-induced animals, there was no excess mortality over control animals (approximately $0.5 \%$ ). With prior induction of the MFO system the rate rose to $6 \%$. When these animals were also pretreated with influenza $B$ virus the mortality rate increased to $19 \%$. [A smaller increase in mortality $(\sim 12 \%)$ was seen in infected D2 mice].

Inflammatory lesions were seen in less than $2 \%$ of the liver samples. Glycogen depletion, recognized on PAS-stained liver sections, was most often associated with severe centrolobular necrosis, but was not specific to any treatment regimen.

$E M$ findings. A total of 70 mouse livers were examined by EM, including livers from B6 and D2 mice, receiving 150 or 200 $\mathrm{mg}$ of acetaminophen plus influenza $\mathrm{B}$ virus and 3-MC. Also examined were livers from untreated animals, and animal receiving: 1) sterile saline alone or in combination with virus, acetaminophen, and/or 3-MC; 2) sterile allantoic fluid alone, or in combination with one of the two other active agents and/or 3-MC.

No remarkable changes were seen in the controls, except in the case of some D2 animals receiving undiluted influenza B virus examined $8 \mathrm{~d}$ after infection. These animals showed an increase in number of microbodies in some cells and some disruptions of the mitochondrial ultrastructure (Fig. 4).

The D2 animals receiving $150 \mathrm{mg}$ acetaminophen plus 3-MC and virus showed some loss of glycogen and slight distention of the endoplasmic reticulum. The D2 animals receiving $200 \mathrm{mg}$

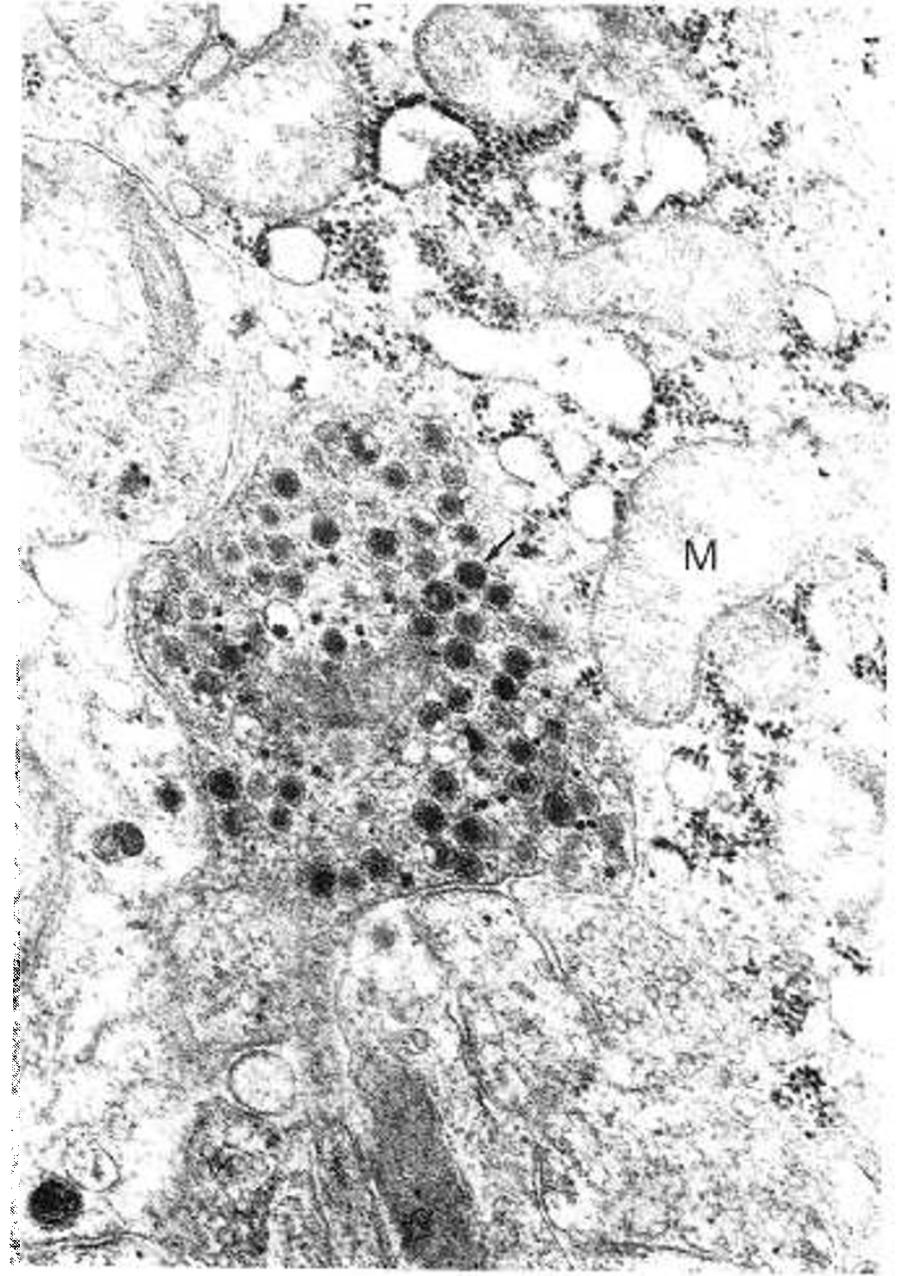

Fig. 4. D2 mouse. Receiving influenza $B$ virus only, showing increase in microbodies (arrow) and some mitochondrial changes $(M)$.

of acetaminophen plus 3-MC and virus showed almost complete loss of glycogen, giving the liver parenchymal cells a moth-eaten appearance. Except for a slight sporadic distention of the ER, the other cytoplasmic organelles were spared (Fig. 5).

The B6 mice receiving acetaminophen, 3-MC, and virus showed profound changes. The B6 animals receiving $150 \mathrm{mg}$ of acetaminophen plus 3-MC and virus showed what appeared to be numerous vacuoles in the cell cytoplasm. Closer examination of these vacuoles revealed the fact that these structures were distentions of the endoplasmic reticulum. Other organelles appeared relatively normal (Fig. 6).

The B6 mice receiving $200 \mathrm{mg}$ of acetaminophen plus 3-MC and virus showed progressive distention of the ER, with almost complete disruption of the normal cytoplasmic architecture in many of the liver parenchymal cells (Fig. 7). In some animals the organelles appeared so profoundly disrupted that many of the cells were dead, and the nuclear ultrastructure showed loss of normal organization. Fatty accumulation, corresponding to the microvesicular steatosis seen on LM, appeared to be within the distended ER (Fig. 6).

These changes seen in the B6 mice were mostly confined to the liver parenchymal cells, but an occasional Kupfer cell showed similar changes. The other cells of the liver, such as the cuboidal epithelial cells of the bile ductules and endothelial cells, appeared unaffected.

Enzyme assays. Arithmetic means of the experimental data were compared using Student's $t$ test, with $P<0.05$ for the twotailed test as the limit of significance. The expected increase in cytochrome $\mathrm{P}-450$ on induction with $3-\mathrm{MC}$ was confirmed. But 


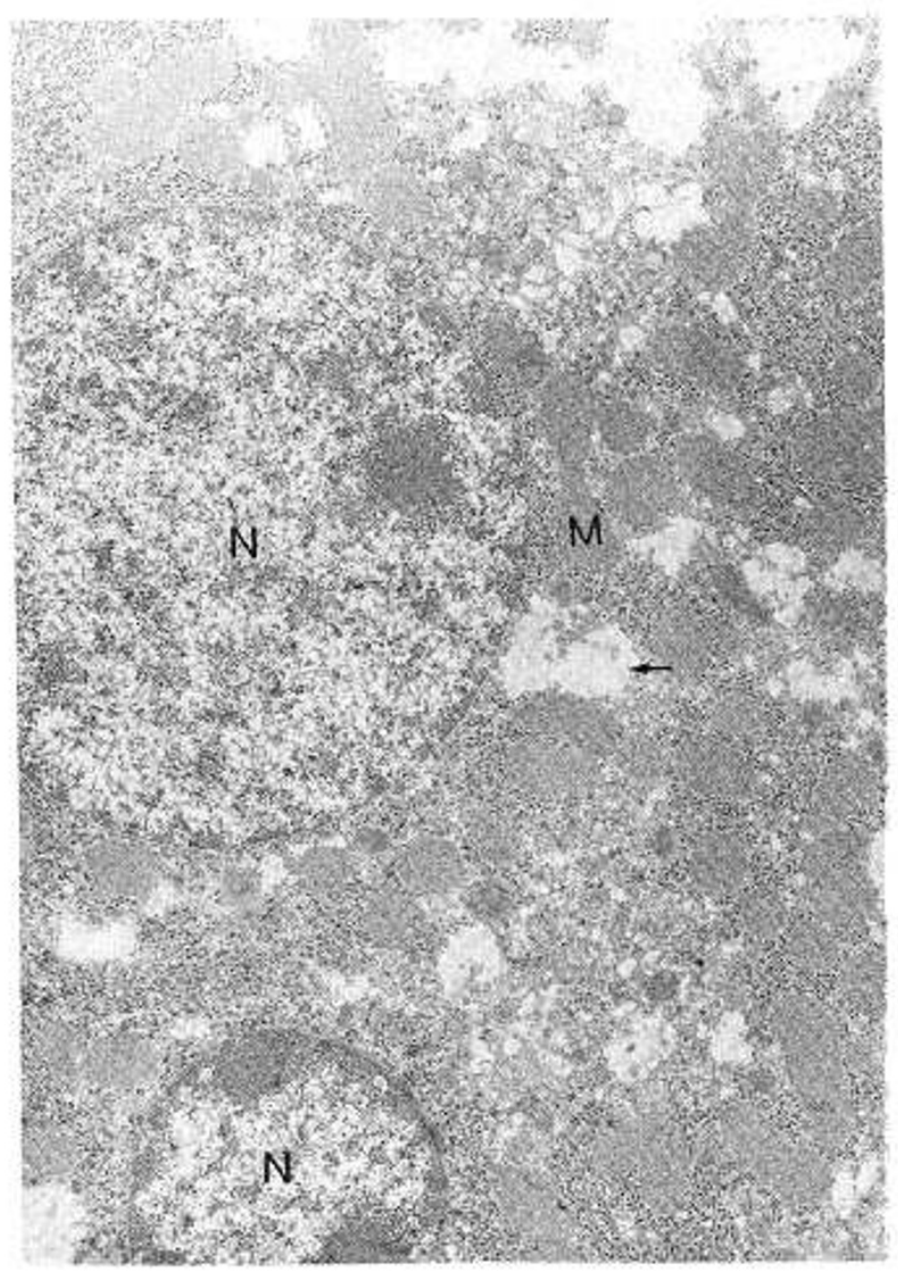

Fig. 5. Hepatocyte from D2 mouse which received 3-MC virus and $200 \mathrm{mg}$ of acetaminophen, showing loss of glycogen (arrow). (N) nucleus and $(\mathrm{M})$ mitochondrium.

no significant change in cytochrome P-450 values was detected as an additional response to viral infection.

Clinical signs. No symptomatology or liver pathology was recognized in animals receiving 3-MC alone, or in combination with influenza B virus. Symptoms were recognized in approximately $5 \%$ of animals receiving all three agents. These consisted of ruffling of the fur, unsteady gait, and terminal irregular respirations. Death, when it occurred spontaneously, tended to be within $36-72 \mathrm{~h}$ after administration of acetaminophen.

\section{DISCUSSION}

This study demonstrates that concomitant infection with influenza $B$ virus has a significant enhancing effect on the hepatic toxicity of acetaminophen in mice. In addition, an atypical fatty liver pathology, resembling that seen in human $\mathrm{RS}$ under the light microscope, appears to result from an unknown interaction between influenza $B$ virus and acetaminophen, in animals whose cytochrome P-450 MFO system is genetically predisposed to induction by aromatic hydrocarbons.

It has been suggested that an individual might be rendered more likely to develop RS as a complication of minor viral infection, by prior contact with chemical environmental pollutants (6). We chose to use 3-MC as representative of aromatic hydrocarbons which are commonly encountered in the environment (e.g., in cigarette smoke and charcoal-broiled meat).

Nonmouse-adapted virus was used because preliminary studies using mouse-adapted virus produced a disease in the mice which

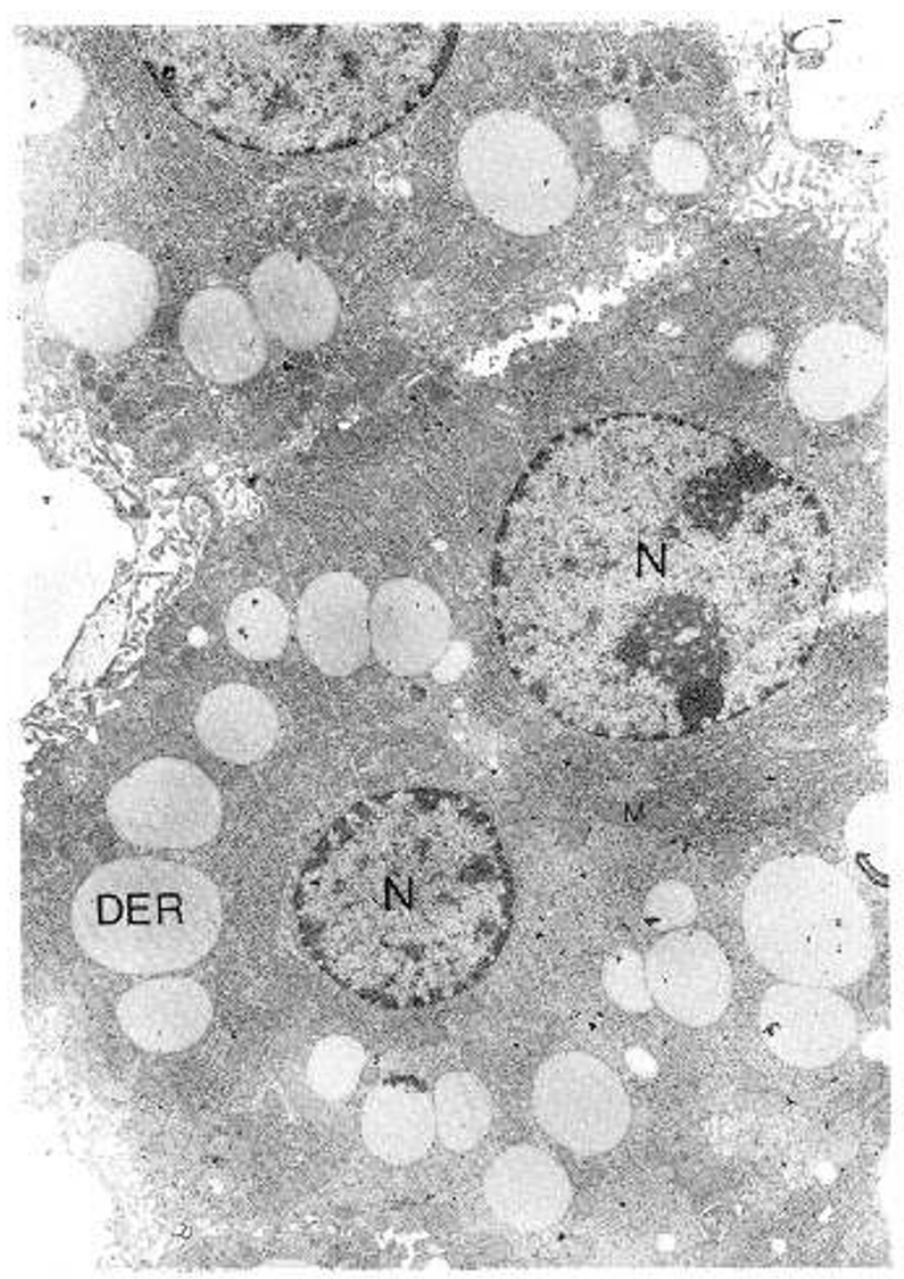

Fig. 6. Hepatocytes from B6 mouse receiving 3-MC, virus, and 150 $\mathrm{mg}$ of acetaminophen showing distention of the endoplasmic reticulum (DER). (N) nucleus and (M) mitochondrium.

was far more severe than typical human disease, i.e., the virus produced severe pneumonia with lung consolidation, associated with a significant mortality.

The finding that dose-related hepatic centrolubular necrosis was potentiated by prior induction of the MFO system in the B6 mice is compatible with previously reported experience (14). Remarkable, however, was finding that a significant number of animals receiving all three study agents showed changes in the liver on light microscopy which were indistinguishable from the microvesicular steatosis described in human RS. This type of fatty infiltration is not typical of the hepatic pathology produced by the toxic metabolite of acetaminophen. Further, in approximately $2 / 3$ of the animals demonstrating the fatty changes, the latter were present without the typical necrotic changes seen in classic acetaminophen hepatotoxicity. Of major interest also, in light of the suggestion that there may be a component of genetic susceptibility rendering an individual more likely to develop RS, is the finding of a significantly greater susceptibility to fatty change in the $\mathrm{B} 6$ as compared with the D2 mice.

The EM examination of the liver from the two strains of mice infected with influenza $B$ virus and treated with the two xenobiotic agents, 3-MC and acetaminophen, showed remarkable differences in susceptibility to the effects of these agents. The changes seen in $D_{2}$ mice without the $A h$ locus were serious, but not as profound as those seen in the Ah suceptible B6 mice, where initial distention of the ER, led to eventual complete disruption of the cells. The disruption of the ER, the site of the MFO cytochrome P-450 enzyme system activity, was only recognized in B6 animals who had received influenza B virus, in 


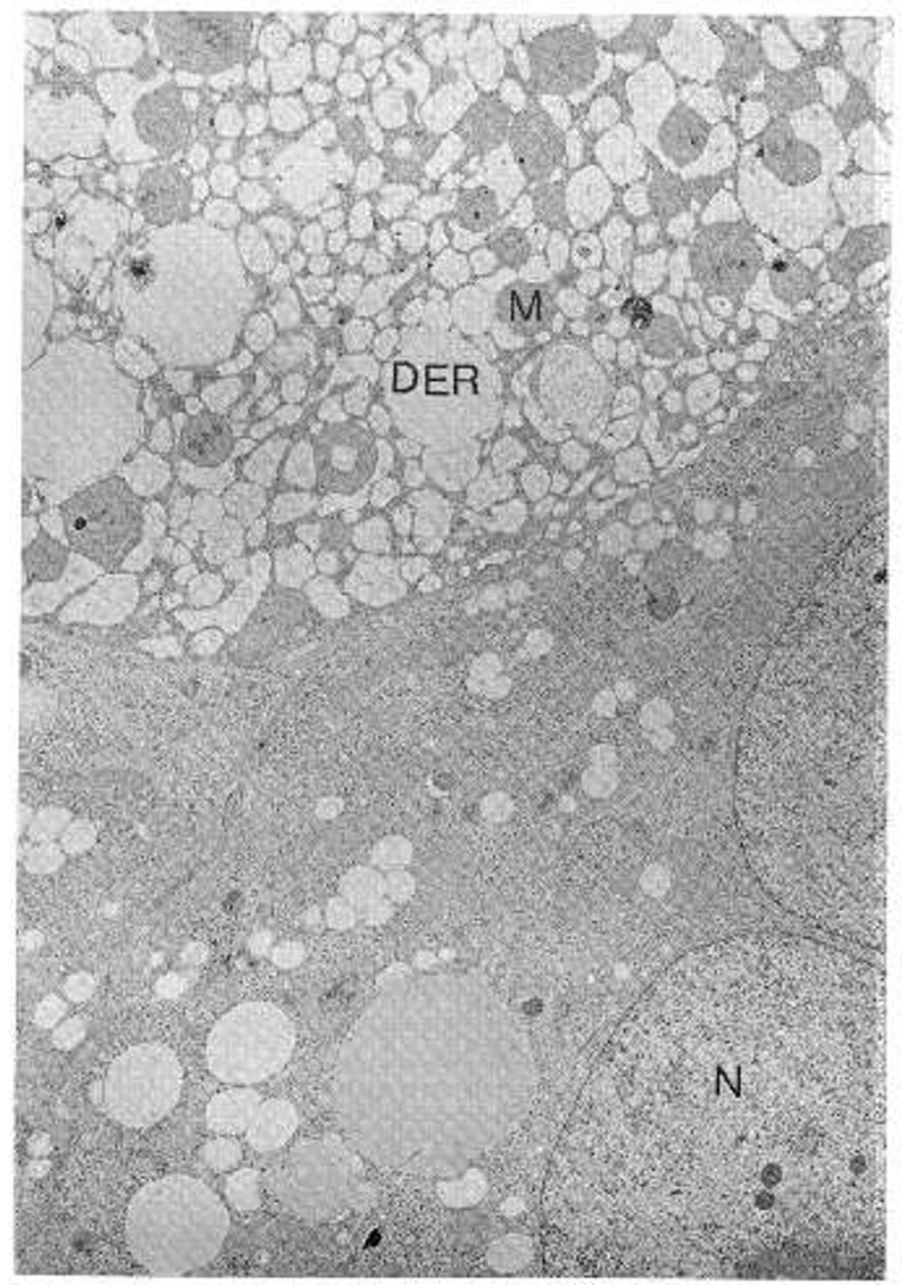

Fig. 7. Hepatocytc from B6 mouse receiving 3-MC, virus, and 200 mg of acetaminophen, with distended endoplasmic reticulum (DER) and ultrastructural alteration of mitochondria (M).

addition to acetaminophen and 3-MC. Similar changes in the ER have been reported on EM examination of the liver of an adult male suffering from acetaminophen overdose, and by Thaler et al. (29) Svoboda et al. (28) in human RS (18). Fat deposits, corresponding to those seen on LM, were within distended areas of the ER.

Svoboda et al. (28) studied the livers of six patients with RS by $\mathrm{LM}$ and EM, and attempted to correlate the changes seen with the clinical course of the disease. They found that on LM, inflammation and necrosis were especially prominent in fatal cases and that "Aside from loss of matrix dense granules, alterations in mitochondrial structure were minimal or absent. No ultrastructural features served to distinguish patients who died from those who survived." They concluded that "Although derangement of mitochondrial function may be important in the pathogenesis of RS, such derangement is not necessarily reflected in the ultrastructure of the mitochondria."

Thaler et al. (29) noted the presence of numerous microbodies in liver cells on EM. They were not impressed by any significant mitochondrial change. Several incomplete reports have been published, such as the one by Morales et al. (15) which merely refers to "mitochondrial changes and dilation of the endoplasmic reticulum."

Structural changes in the hepatic cell mitochondria in RS have been emphasized by Partin et al. (26). These authors believe that there is a parallel between recovery of mitochondrial ultrastructure and clinical improvement of the patient, and suggest that mitochondrial damage is important in the evolution of RS.
Although mitochondrial changes did become apparent with progression of the toxic process in our study mice, they were invariably preceded by swelling of the ER. Our findings resemble those described by Svoboda et al. (28) and to a lesser extent by Thaler et al. (29). Direct comparison of our mouse samples with liver samples from humans was handicapped by the lack of availability of human biopsy specimens, because liver biopsy is no longer regarded as a routine procedure in diagnosing $\mathrm{RS}(22)$. Our review of published EMs led us to conclude that dilatation of the ER preceeds significant hepatic mitochondrial damage in the progression of human RS, but that the ER changes are often overlooked by the authors when describing EM findings.

Studies to date on the effects of drug-virus interaction on the immune system have indicated that stimulation of interferon production by the virus will depress the MFO system (7, 12, 20). Our histologic data suggest that activation of certain components of the cytochrome P-450 MFO system might be a mechanism for potential acetaminophen toxicity in our study mice. In light of this, the results of cytochrome P-450 enzyme assays are contrary to expectations; however, interpretation is handicapped by methodologic problems. It was our intention to attempt to correlate cytochrome P-450 values, not only with individual treatment regimens, but also with histologic findings in the individual mouse livers. This was the reason for attempting enzyme estimations on the same livers from which samples were obtained for LM and, in some cases, EM. In fact, enzymehistology correlation was not possible, because animal livers had to be pooled in order to separate sufficient microsomal material for subsequent enzyme assay. Although our results do not indicate that microsomal P-450 induction is a mechanism by which the toxic effects of acetaminophen are potentiated by influenza $B$ virus in these animals, it is certainly possible that studies of larger numbers of animals and use of more sensitive methods for enzyme assay, along with methodology to separate out individual types of P-450, might produce differing results.

The pitfalls of direct extrapolation from animal data to the human are well recognized. But, the finding that the typical liver toxicity of acetaminophen is significantly enhanced in mice by concomitant viral infection is of major potential significance to the human. Animal studies by McLain et al. (13) and Goldfinger et al. (9), on the combined effects of alcohol and acetaminophen have been confirmed in humans. Alcoholic subjects may suffer serious toxic effects from usually innocuous quantities of acetaminophen, particularly if they are abusing other chemical substances. Acetaminophen toxiciy also appears to be potentiated by concomitant mononucleosis (23).

Acetaminophen is a commoly used antipyretic in children and is being promoted in the United States. This promotion is being facilitated by the apparent indictment of salicylates as a causal agent in RS (21). The evidence that other commonly used drugs are not etiologically associated with RS is extremely weak.

Taking into consideration the numerous agents which have been causally related to an RS-like syndrome in man, we hypothesize that viral-xenobiotic interaction may be an underlying mechanism by which many foreign chemicals might produce RS in a susceptible individual (27). Those affected may have rendered susceptible by prior contact with some noxious environmental substance, and/or by genetic factors, perhaps manifested through the immune system.

\section{REFERENCES AND NOTES}

I. Atlas. S. A.. Vessell, E.S. and Nebert, D. W.: Genetic control of interindividual variations in the inducibility of aryl hydrocarbon hydroxylase in cultured human lymphocytes. Cancer Res, 36: 4619 (1976)

2. Brown, R. E. and Madge, M. D.: The pathology of Reye's syndrome: An overview. In: D. J. Pollack: Reye's syndrome. p. 77 (Grune and Stratton, New York, 1974.)

3. Chalkley H. W.: Method for the quantitative morphologic analysis of tissues. J. Natl. Cancer Res., 4: 47 (1943).

4. Colon, A. R., Ledesma, F., Pardo, V., and Sandberg, D. H.: Viral potentiation of chemical toxins in the experimental syndrome of hypoglycemia, enceph- 
alopathy and fatty visceral degeneration. Am. J. Dig. Dis., 19: 1091 (1974).

5. Crocker, J. F. S., Rozee, K. R., Ozere, R. L., Digout, E. S., and Hutzinger, O. Insecticide and viral infection as a cause of fatty visceral changes and encephalopathy in the mouse. Lancet 2: 22 (1974).

6. Crocker, J. F. S., Berg, H. R. M., MacDonald, R. G., Ozere, R. L., and Ecobichon, D. J.: Reye's syndrome: A disease of chemical and viral interactions. In: D. J. Pollack: Reye's syndrome. pp. 331-541 (Grune and Stratton New York, 1974)

7. Deloria, L. B. and Mannering, G. J.: Sequential administration of polyriboinosinic acid and polyribocytidylic acid induce interferon and depress the hepatic cytochrome P.450 dependent monoxygenase system. Biochem. Biophys. Res. Commun. 106: 947 (1982).

8. Friend, M. and Trainer, D. O.: Polychlorinated Biphenyl: interaction with duck hepatitis virus. Science, 170: 1314 (1970).

9. Goldfinger, R., Ahmed, K. S., Pitchumoni, C. S., and Weseley, S. A.: Concomitant alcohol and drug abuse enhancing acetaminophen toxicity. Am. J Gastroenterol., 70: 385 (1978).

10. Gurevitz, M.. Tombaugh, G. C., and Schwartz, K. B.: Reye's syndrome model in rats with phosphorus $\left(\mathrm{P}_{4}\right)$. Pediatr. Res. (abstract), 16: 164 (1982).

11. Kellerman, G., Shaw, C. R., and Lyten-Kellerman, M.: Aryl hydrocarbon hydroxylase inducibility and bronchogenic carcinoma. N. Engl. J. Med., 289: 934 (1973)

12. Kramer, M. J., Furukawa, C. T., Karp, J. R., Shapiro, G. G., Pierson, W. E., and Bretman. C. W. Altered theophylline clearance during an influenza B outbreak. Pediatrics, 69: 476 (1982).

13. McLain, C. J.. Kromhout, J. P., Petersen, F. J., and Holtman, J. L.: Potentiation of acetaminophen hepatotoxicity by alcohol. J. Am. Med. Assoc., 244: 25 (1980).

14. Mitchell, J. R., Jollow, D. J., Potter, W. Z., Gillette, J. R., and Brodie B. B. Acetaminophen-induced hepatic necrosis: I-IV. J Pharmacol. Exp. Ther. 187: 185 (1973).

15. Morales, A. R., Bourgeois, C. H., Jr., Trapukdi, S., and Chulacharite, E. Encephalopathy and fatty degeneration of the viscera. An electron Microscopic study. Am. J. Clin. Pathol., 52: 755 (1969).

16. Mullen, P. W.: Immunopharmacological considerations in Reye's syndrome a possible xenobiotic initiated disorder? Biochem. Pharmacol., 27: 145 (1978).

17. Omura, $T$ and Sato $R$. The carbon monoxide binding pigments of liver microsomes. J. Biol. Chem. 239: 2370 (1964).

18. Peterson, P. and Vilstrup, H.: Relation between liver function and hepatocyte ultrastructure in a case of paracetamol intoxication. Digestion, 19:415 (1979).

19. Pollack, J. D. Models of chemical and virus interaction and their relation to a multiple etiology of Reye's syndrome. In: J. F. S. Crocker: Reye's syndrome II. pp. 341-360 (Grune and Stratton, New York, 1979).

20. Renton, K. W.: Effects of Infection and Immune Stimulation on Theophylline Metabolism. Semin. Perinatol., 5: 378 (1981).

21. Report on the scientific workshop on Reye's syndrome and its possible association with salicylate use. Department of Health and Human Services.
Public Health Service, Food and Drug Administration Held May 24th 1982, at National Institutes of Health.

22. Reye's Syndrome: National Institute of Health Consensus Development Conference. March 1981.

23. Rosenberg, D. M., Meyer, A. A., Manning, I. H., and Neelon, F. A.: Acetaminophen and hepatic dysfunction in infectious mononucleosis. South. Med. J., 70: 660 (1977).

24. Ruben, F. L.: Recent developments and contributions from experimental models of Reye's syndrome. In: J. F. S. Crocker: Reye's Syndrome II. pp 385-397 (Grune and Stratton Inc., New York, 1979).

25. Schacterle, G. R. and Pollack, R. L.: A simplified method for the quantitative assay of small amounts of protein in biologic material. Anal. Biochem., 51 : 654 (1973).

26. Schubert, W. K., Partin, J. C., and Partin J. S.: Encephalopathy and fatty liver (Reye's syndrome). In: H. Popper and F. Schaffner: Progress in Liver Diseases. Vol. 4. pp 489-493. (Grune and Stratton New York, 1972).

27. Sullivan-Bolyai, J. Z. and Corey, L.: Epidemiology of Reye's syndrome. Epidem. Rev. 3: 126 (1981).

28. Svoboda, D. J. and Reddy, J. K.: Pathology of the liver in Reye's Syndrome. Lab. Invest. 32: 571 (1975).

29. Thaler, M. M., Bruhn. F. W., Appelbaum, M. N., and Goodman, J.: Reye's syndrome in twins. J. Pediatr., 77: 638, (1970).

30. Thorgeirsson, S. S., Felton, J. S., and Nebert. D. W.: Genetic differences in the aromatic hydrocarbon-inducible n-hydroxylation of 2 -acetylamino flourene and acetaminophen produced hepatotoxicity in mice. Mol. Pharmacol. . II 159 (1975).

31. Thorgeirsson, S. S. and Nebert, D. W.: The Ah locus and the metabolism of chemical carcinogens and other foreign compounds. Adv. Cancer Res., 25. 149 (1977).

32. Webb, S. R. Hartig, P. C., Bryson, M. S., Llewellyn, G. C., and Madge, G. E. Reye's syndrome-like disease in mice fed aflatoxin and infected with Coxsackie virus. Presented at the Reye's syndrome III Symposium: Detroit. November, 1980.

33. In order to obtain a microsomal pellet of sufficient size for enzyme assay, i was found necessary to pool the livers from a minimum of three animals.

34. Using Stepwise Progressive Logistic Regression, all comparisons quoted in be were significant to $P<0.001$.

35. Centrolobular necrosis was considered significant when it was clearly recognized in $10 \%$ or more of the hepatic lobules examined.

36. The authors thank Drs. D. W. Nebert and C. McLaren for their invaluable advice and support for the project.

37. Requests for reprints should be addressed to: Dr. Mhairi G. MacDonald, Children's Hospital National Medical Center, 111 Michigan Avenue, N.W. Washington, D.C. 20010.

38. This research was supported by the Division of Developmental Pharmacology, NICHHD, and the Bureau of Biologics. FDA.

39. Reccived for publication February 8,1983

40. Accepted for publication August 17, 1983

\section{ANNOUNCEMENT}

The annual meeting of the American Society of Pediatric Nephrology will be held at the Hilton Hotel in San Francisco on Tuesday, May 1, 1984, from 9:00 a.m. to 5:30 p.m. The morning session of the symposium will focus on reflux nephropathy-anatomical, bacteriological, genetic and radiological implicationsand the afternoon session will cover prostaglandins in newborn physiology and renal function. For further information, please contact Dr. Russell Chesney, Secretary-Treasurer, American Society of Pediatric Nephrology, University of Wisconsin Clinical Science Center (Rm H4/452), 600 Highland Avenue, Madison, Wisconsin 53792. 